\title{
PERCEPÇÃO DA COMUNIDADE DA UNIVERSIDADE FEDERAL DO PARANÁ EM RELAÇÃO ÀS MUDANÇAS CLIMÁTICAS
}

\author{
FEDERAL UNIVERSITY OF PARANÁ COMMUNITY PERCEPTION ON CLIMATE CHANGE
}

\author{
Carlos Roberto Sanquetta ${ }^{1}$, Milena Pereira Kozlowski \\ 1, 2 Universidade Federal do Paraná, Curitiba, Paraná, Brasil-sanquetta@ufpr.br \& \\ kozlowskimilena@gmail.com
}

\begin{abstract}
RESUMO
O assunto das mudanças climáticas é amplamente discutido atualmente, mostrando a importância do mesmo. As Universidades são vistas como geradoras de conhecimento e de profissionais que farão parte do mercado de trabalho a curto, médio e longo prazo. Portanto, é imprescindível que se realize um diagnóstico do conhecimento da comunidade acadêmica quanto às mudanças climáticas, o qual foi objeto do presente estudo. Para isto, criou-se um formulário contendo perguntas fechadas a respeito da percepção de risco, de urgência e de responsabilidade quanto às mudanças climáticas. Trata-se de uma amostra não-probabilística e intencional, pois o público-alvo era de pessoas diretamente ligadas à Universidade Federal do Paraná (UFPR). Em geral, a comunidade acadêmica da UFPR possui um conhecimento considerado intermediário das mudanças climáticas e reconhece a importância do assunto. As principais fontes de conhecimento utilizadas são a internet, a televisão e a própria Universidade, demonstrando a importância das mídias sociais na formação de conhecimento técnico e crítico. A maioria da amostra acredita que as atividades humanas influenciam o clima terrestre e que uma das principais atividades que podem agravar a situação é o desmatamento. Além disso, a principal responsabilidade com relação à tomada de decisão e ação com relação às mudanças climáticas foi direcionada a órgãos públicos, instituições privadas e órgãos internacionais. A amostra demonstra compreender os principais conceitos, causas e consequências ligados às mudanças climáticas. Com os resultados obtidos, pode-se fazer uma melhor curadoria de assuntos a serem tratados em uma possível campanha de conscientização.
\end{abstract}

PALAVRAS-CHAVE: Adaptação, Alterações Climáticas, Clima, Mitigação, Universidade.

\begin{abstract}
Climate change is currently a subject that is highly discussed. Universities are seen as knowledge creators and are the institutions responsible for the formation of professionals that will be in the job market in the short, medium, and long term. That is why it is necessary to make a diagnostic on what the academic community thinks and knows about climate change. Therefore, an online survey took place to gather information about the academic perception on climate change at the Federal University of Paraná (UFPR) in Curitiba, Brazil. The main public had a direct relationship with the university, such as being its professors, students, or staff. In general, the community has an intermediate level of knowledge about climate change and recognizes its overall importance. The main sources used to learn about it are the internet, the television, and the University itself, which shows the importance of social media as a creator of technical and critical opinion nowadays. Most of the sample believes that human activities can influence the climate and that deforestation may be one of its main causes. Most of the sample also believes that public institutions are the main responsible for tackling the climate change problem, then comes private organizations and international bodies. In conclusion, the community seems to understand the main concepts, causes and consequences of climate change. The results obtained give relevant information for creating tailored projects to this public as it is already known what they think about the subject.
\end{abstract}

KEYWORDS: Adaptation, Climate Change, Climate, Mitigation, University. 


\section{INTRODUÇÃO}

A concentração dos gases de efeito estufa (GEEs) é a maior observada em 800 mil anos, de acordo com o Painel Intergovernamental sobre Mudanças Climáticas (IPCC). Além disso, metade das emissões ocorridas entre 1750 e 2011 foram liberadas nos últimos 40 anos. Tais informações demonstram o impacto antropogênico no clima terrestre. A presença de GEEs na atmosfera influenciam na absorção e retenção de calor pelo planeta, o que causa alterações no clima. Uma das alterações mais visíveis é o aumento da temperatura. As últimas três décadas foram as mais quentes desde 1850 (IPCC, 2014). Desta forma, a probabilidade da ocorrência de eventos climáticos extremos, severos e irreversíveis será maior caso as emissões não sejam reduzidas. Para tal, existem as ações de mitigação e adaptação às mudanças climáticas. Uma das medidas de adaptação propostas pelo IPCC (2014) diz respeito ao aumento do conhecimento social sobre as mudanças climáticas. Para tal, torna-se necessário estudar qual o nível de conhecimento da população atual, visando reconhecer os pontos de melhoria na comunicação e no processo de educação a respeito do assunto.

A falta de conhecimento sobre $o$ assunto e a divergência entre valores e comportamentos sociais e culturais impedem que haja um consenso social sobre os riscos das mudanças climáticas, tornando-se uma barreira tanto com relação à percepção de risco quanto à falta de ações por parte da população (BARBOSA et al., 2018). Essa divergência entre valores e comportamentos dificulta a estruturação de demandas comunitárias para políticas e medidas públicas de adaptação (IPCC, 2014), pois deve-se considerar o contexto de cada grupo para, então, estruturar e propor soluções para os problemas sociais ligados às mudanças climáticas. Ademais, antes de propor soluções, a população necessita primeiramente compreender os riscos aos quais está exposta, aprendendo então como pode contribuir para compreender e tomar as devidas medidas de ação (LENZHOLZER et al., 2020).

Neste momento, percebe-se a importância de estudos da percepção climática da população. Ao conhecer e entender seus valores e comportamentos pode-se criar formas de comunicação e medidas mais adaptadas a cada nação e grupo de pessoas, aumentando o engajamento dos mesmos (COELHO, 2004; PIDGEON, 2012; LEE et al., 2015; ERNOUL, 2020; RUIZ et al., 2020; RUZ et al., 2020). A importância de estudos neste quesito deve-se, principalmente, pois os indivíduos e a sociedade na qual estão inseridos têm papel essencial no momento da implementação de políticas públicas, podendo servir como agentes facilitadores ou podendo dificultar a ação (CLAYTON et al., 2015; ANTRONICO et al., 2020).

Até o momento, alguns estudos foram realizados quanto à percepção brasileira sobre as mudanças climáticas. Estudos nacionais, como os realizados pelo Instituto de Tecnologia \& Sociedade do Rio de Janeiro (ITS - Rio), o Programa da Comunicação das Mudanças Climáticas da Universidade de Yale e a IBOPE Inteligência, e internacionais, como o realizado pela parceria entre o Departamento de Sociologia da Universidade de Oxford e o Programa de Desenvolvimento das Nações Unidas.

O número de pesquisas realizadas com o público universitário ainda é incipiente, as principais pesquisas sendo de Bursztyn \& Eiró (2015) na Universidade de Brasília e a realizada por Barbosa et al. (2018) especificamente com alunos de educação física. O foco de grande parte das pesquisas sobre percepção tem sido instituições de ensino fundamental e médio (STÜRMER et al., 2010; PINHEIRO et al., 2018), comunidades locais (BRAGA et al., 2011; RUZ et al., 2020), populações em países específicos (SHI et al., 2015) ou considerando, simultaneamente, populações de diversos países (SHI et al., 2016; LENZHOLZER et al., 2020).

Investigar o conhecimento da comunidade acadêmica se torna então necessário para compreender o que pensa essa parcela da população e quais as melhores maneiras de abordá-la em projetos de conscientização. Desta maneira, o objetivo do atual trabalho foi realizar a coleta e análise de informações específicas a respeito das mudanças climáticas para melhor entender a percepção da comunidade universitária sobre 0 assunto. Tais informações podem auxiliar na criação de projetos de conscientização climática mais adaptados, aumentando assim a participação e engajamento de seus participantes.

\section{MATERIAL E MÉTODOS}

O método de formulários mostrou-se eficiente para a coleta de dados quantitativos em estudos similares (BRAGA et al., 2011; MELLO et al., 2012; SHI et al., 2015; PINHEIRO et al., 2018; RUZ et al., 2020), sendo a metodologia adotada. O formulário era composto principalmente de questões fechadas e de múltipla escolha, assim como feito por Braga et al. (2011) e Ribeiro et al. (2014), possibilitando melhor segmentação e posterior análise dos dados.

O formulário online foi criado a partir da plataforma Formulários Google ${ }^{\circledR}$ e distribuído para alunos, professores e profissionais técnicos da Universidade Federal do Paraná, localizada em Curitiba, Paraná. Trata-se de uma amostra 
não-probabilística intencional, tendo em vista que o público-alvo era de pessoas diretamente relacionadas à Universidade. A distribuição do formulário foi a partir das mídias sociais (Facebook, Instagram e WhatsApp) pessoais e da própria Universidade, além do envio por e-mail aos diferentes grupos estudantis pertencentes à Universidade (Grupos PET, Empresas Juniores, Centros Acadêmicos, entre outros) e professores. O formulário ficou disponível durante três semanas, coletando 466 respostas sendo que nenhum incentivo foi oferecido aos respondentes.

As questões do formulário foram separadas em seis diferentes categorias. O primeiro grupo de perguntas visou a caracterização socioeconômica dos respondentes e sua relação com a universidade.

A segunda seção objetivou entender o conhecimento dos indivíduos sobre as mudanças climáticas, assim como os conceitos por trás do assunto, as principais fontes de comunicação utilizadas para o estudo do assunto, e o impacto gerado por cada causa previamente listada.

Após, desejou-se saber qual o entendimento dos principais conceitos com relação às mudanças climáticas, utilizando a escala de concordância total ou parcial, indiferença, discordância total ou parcial. Ainda neste grupo de questões, foi indagada qual a importância que o respondente dava a cada causa listada, tais como o uso de combustíveis fósseis, a agropecuária, o desmatamento (considerando as queimadas), a urbanização, os processos industriais, o tratamento de resíduos e o uso de energia. Foi utilizada uma escala com relação ao impacto de cada causa, variando de "nenhum impacto" até "muito impacto" para cada uma.

A terceira categoria de perguntas tinha como objetivo entender se o indivíduo havia experienciado eventos climáticos extremos e como isso poderia influenciar a sua percepção temporal e espacial da probabilidade do aumento de tais eventos. Neste caso, tratava-se de uma questão com múltiplas escolhas, podendo o indivíduo ter experienciado mais de um evento em sua vida. Por esta razão, utilizou-se a escala variando de nunca ter experienciado alguma das situações listadas, ter sentido pouco impacto em sua vida, ter sentido um impacto intermediário ou ter sentido muito impacto.

Além disso, adicionou-se uma resposta nomeada como "nunca, mas sei que existe", principalmente considerando os eventos de tornados, ciclones e furacões, menos presentes no Brasil, podendo o respondente ter escutado a respeito desses eventos em outros países a partir de meios de comunicação, como a televisão. Logo após, desejou-se saber sobre a noção temporal e espacial que as pessoas possuem a respeito do aumento da frequência de eventos extremos. O objetivo era entender quando as pessoas acreditam que isso vai se tornar mais frequente e onde, se mais próximo delas ou não, visando confirmar o conceito de otimismo espacial e temporal levantado por Pinheiro et al. (2018).

O quarto bloco de questões procurou compreender a opinião dos respondentes quanto aos diferentes níveis de responsabilidade de diversos agentes e instituições. As perguntas consideravam atores como o próprio indivíduo, a comunidade, o governo (estado e país), órgãos internacionais, empresas, escolas, universidades e organizações não governamentais (ONGs). A escala utilizada foi com relação ao impacto das ações de cada um desses agentes, variando de nenhum impacto até muito impacto, tentando entender o nível de responsabilidade de cada um com relação ao combate das mudanças climáticas.

O quinto grupo trabalhou com perguntas relacionadas à importância da realização de ações individuais, quais ações o indivíduo aplica atualmente e, se ainda não aplica, quais os impedimentos para tal. Questões sobre os impactos de ações de mitigação realizadas em diferentes escalas (individual e coletiva) também foram perguntadas nesta seção e serão detalhadas em posteriores estudos.

Foi questionada também qual a opinião dos respondentes quanto ao papel e as ações que os governos deveriam tomar com relação ao combate das mudanças climáticas. A escala utilizada neste caso foi com relação à necessidade de cada ação descrita anteriormente, podendo ser considerada como desnecessária, pouco necessária, meio necessária ou muito necessária.

Por fim, questionou-se por quais meios de comunicação os respondentes gostariam de ser informados, objetivando entender as diferentes formas de abordagem do assunto para uma comunicação mais efetiva do mesmo para a população.

Após exportação dos dados do Formulários Google ${ }^{\circledR}$ para o Microsoft Excel ${ }^{\circledR}$, os mesmos foram revisados, uniformizados e divididos de acordo com as seções presentes no formulário. Em seguida, ocorreu a análise dos dados, realizada igualmente no Microsoft Excel ${ }^{\circledR}$, com o uso de tabelas dinâmicas e criação de gráficos para melhor visualização dos resultados.

\section{RESULTADOS E DISCUSSÃO}

Os participantes da pesquisa eram majoritariamente jovens, com idade entre 18 e 25 anos, do gênero feminino, graduandos (Tabela 1), tendo ensino médio completo e renda mensal de $\mathrm{R} \$ 0,00$ a $\mathrm{R} \$ 1.264,00$, fazendo parte da Classe econômica E segundo a Fundação Getúlio Vargas 
(2014) (Tabela 2).

Tabela 1. Caracterização da amostra quanto à faixa etária, gênero e cargo dentro da Universidade.

\begin{tabular}{ccc}
\hline Idade & $\mathbf{N}^{\circ}$ respostas & Porcentagem \\
\hline $18-25$ & 305 & $65,5 \%$ \\
\hline $26-30$ & 40 & $8,6 \%$ \\
$31-40$ & 52 & $11,2 \%$ \\
\hline $41-50$ & 31 & $6,7 \%$ \\
\hline $51-60$ & 28 & $6,0 \%$ \\
\hline$>61$ & 10 & $2,1 \%$ \\
\hline Gênero & $\mathbf{N}^{\circ}$ respostas & Porcentagem \\
\hline Feminino & 260 & $55,8 \%$ \\
\hline Masculino & 204 & $43,8 \%$ \\
\hline Outros & 2 & $0,4 \%$ \\
\hline Cargo & $\mathbf{N}^{\circ}$ respostas & Porcentagem \\
\hline Graduando & 367 & $78,8 \%$ \\
\hline Pós-Graduando & 16 & $3,4 \%$ \\
\hline Professor & 62 & $13,3 \%$ \\
\hline Técnico & 19 & $4,1 \%$ \\
\hline Outros & 2 & $0,4 \%$ \\
\hline
\end{tabular}

Quase metade $(42,9 \%)$ da amostra possui um nível intermediário de conhecimento quanto às mudanças climáticas e menos de $10 \%$ dizem ter um conhecimento amplo do assunto. Barbosa et al. (2018) encontrou valores similares, sendo que, em seu estudo, $50 \%$ da amostra demonstrou ter um conhecimento intermediário do assunto. Stürmer et al. (2010) e Xue et al. (2020) encontraram resultados, onde $80 \%$ e $75 \%$ da amostra, respectivamente, demonstraram possuir conhecimento intermediário sobre os riscos ligados às mudanças climáticas. Nestes outros estudos, a grande maioria diz possuir nível intermediário, enquanto no presente estudo a taxa é menor que a metade da amostra. Isto pode ser explicado pelo uso de diferentes escalas de avaliação do nível de conhecimento, podendo o presente estudo ter utilizado uma escala possuindo mais opções do que as pesquisas apresentadas.

Com relação à importância dada ao assunto, mais da metade $(55,1 \%)$ considera o assunto muito importante atualmente, valor menor do que o encontrado pelo ITS-Rio, onde $78 \%$ consideram o aquecimento global muito importante. Entretanto, no presente estudo foi perguntada a importância das mudanças climáticas como um todo, não apenas do aquecimento global, como no estudo no ITS-Rio, podendo ser uma das razões pela qual o resultado encontrado foi menor. Em Ribeiro, Olcina \& Molina (2014) e Barbosa et al. (2018) mais da metade da amostra (73\%) considerou o assunto como muito importante, mostrando que se trata de um assunto considerado de grande importância pela maior parte das amostras estudadas.

Tabela 2. Informações a respeito da renda e grau de escolaridade da amostra.

\begin{tabular}{cc|c|}
\hline Renda & $\mathbf{N}^{\circ}$ respostas & Porcentagem \\
\hline$\$ 0-\$ 241.30$ & 136 & $29,2 \%$ \\
\hline $241.31-\$ 385.60$ & 63 & $13,5 \%$ \\
\hline $385.61-\$ 1,662.60$ & 121 & $26,0 \%$ \\
\hline$\$ 1,662.61-\$ 2,166.95$ & 46 & $9,9 \%$ \\
\hline Mais que \$2,166.96 & 52 & $11,2 \%$ \\
\hline Prefere não dizer & 48 & $10,3 \%$ \\
\hline Grau de Escolaridade & $\mathbf{N}^{\circ}$ respostas & Porcentagem \\
\hline Ensino Médio Completo & 366 & $78,5 \%$ \\
\hline Ensino Superior Completo & 23 & $4,9 \%$ \\
\hline Pós-Graduação & 77 & $16,5 \%$ \\
\hline
\end{tabular}

Com relação às fontes de conhecimento utilizadas onde se teve contato com o assunto, as três principais são a internet, televisão e a própria Universidade. Para Stürmer (2010), as principais fontes de informação de sua amostra eram a televisão e as aulas em sala de aula. Assim como Ernoul (2020), onde os principais meios de obtenção de informação eram igualmente a televisão, seguida de rádios, jornais e a internet. Para Antronico et al. (2020) as principais fontes de conhecimento foram a televisão, a internet e o meio social. Apesar da diferença entre os meios utilizados nas diferentes pesquisas, a televisão é um meio presente, ficando na segunda posição apenas no presente estudo. Além disso, a internet se mostra na maioria dos estudos apresentados, provando igualmente que se trata de uma importante base de informações sobre o assunto. A televisão ainda era, em 2019, a fonte de informação mais presente nos lares brasileiros $(96,3 \%)$, atrás da internet, com $82,7 \%$ dos domicílios possuindo acesso à mesma, segundo o Instituto Brasileiro de Geografia e Estatística (IBGE, 2019). Nota-se igualmente o importante papel das instituições de ensino, no presente caso sendo a Universidade e no caso de Stürmer (2010) a escola na instrução dos indivíduos quanto ao assunto.

Feygina et al. (2020) perceberam que o conhecimento e a percepção de risco aumentam a partir do contato do indivíduo com relatórios climáticos televisivos. Aqueles que assistiram a um relatório climático com informações detalhadas afirmaram em seguida que as mudanças climáticas estão ocorrendo, têm influência humana, causam ameaças no meio ambiente individual e são um assunto importante. Estas pessoas mostraram-se também 
mais abertas a aprofundar seus conhecimentos sobre o assunto. Ressalta-se a importância dos meios de comunicação na difusão de conhecimento e na construção da percepção e opinião social (BURSZTYN \& EIRÓ, 2015; ANTRONICO et al., 2020). Eles encontraram resultados de percepção homogêneos, principalmente devido à comunicação em massa, o que reforça o papel destas mídias na formação da opinião pública.

Os conceitos apresentados no formulário tratam principalmente das causas e consequências das mudanças climáticas. Sendo apresentadas três frases para que o respondente diga seu nível de concordância com cada uma delas. O primeiro conceito, resumido no gráfico como Eventos Extremos representa a seguinte frase presente no formulário "As mudanças climáticas são a causa do aumento de eventos climáticos extremos, tais como secas, enchentes, tempestades, calor extremo, etc.", a categoria Causa Humana estava presente como "As mudanças climáticas são consequência da ação humana e seus impactos sobre o planeta Terra" e, representado por Causa natural, a frase "As mudanças climáticas são eventos naturais que ocorrem no planeta, sem nenhum impacto da ação humana" (Figura 1). Os conceitos foram colocados prontos visando reduzir a heterogeneidade das respostas e, portanto, uma melhor categorização e análise dos dados e resultados.

Figura 1. Nível de concordância da amostra com relação a três conceitos apresentados sobre mudanças climáticas.

\section{Percepção quanto ao conceito das} mudanças climáticas



Os resultados encontrados em todos os conceitos propostos contaram com quase metade da amostra concordando totalmente, parcialmente ou discordando totalmente das afirmações. Para a primeira afirmativa (eventos extremos), 48\% dos respondentes concordaram plenamente. Para a segunda (causa humana), a proporção encontrada para concordância parcial (47\%) foi pouco maior que para concordância total (46\%), ainda assim a concordância foi maior que a discordância. Já na terceira afirmação (causa natural), grande parte (45\%) discorda plenamente da frase proposta. Estes resultados mostram que grande parte da amostra tende a escolher um lado e a concordar ou discordar do assunto, raramente tendo uma opinião indiferente. Além disso, a proporção de pessoas concordando para a primeira e segunda alternativas é similar à quantidade de indivíduos discordando sobre a terceira alternativa. Estes valores não são os mesmos por conta de os conceitos não serem excludentes, o que quer dizer que pessoas podem concordar totalmente que as mudanças climáticas possuem causas antrópicas, mas podem concordar parcialmente que a natureza também age sobre o assunto, por exemplo.

Tem-se então que a maior parte dos respondentes acreditam que as mudanças climáticas aumentarão a frequência de eventos extremos e são causadas principalmente por ações humanas. Tais conclusões corroboram com as encontradas pelo ITS - Rio (2020), onde $77 \%$ dos respondentes afirmam que as mudanças climáticas são consequências das ações humanas. Os resultados concordam também com os encontrados por Mello et al. (2012), Ribeiro et al. (2014), Barbosa et al. (2018), Antronico et al. (2020) e Ernoul (2020). Há um consenso de que as ações antrópicas têm influência sobre o clima terrestre, assim como presente no Quinto Relatório de Avaliação do IPCC (2014).

No que diz respeito ao impacto das causas das mudanças climáticas, cada causa citada foi considerada de maneira independente, ou seja, considerando as 466 respostas obtidas como $100 \%$ para cada causa (Figura 2).

As causas com maior impacto, consideradas por mais da metade (>50\%) da amostra, foram as ações de desmatamento (considerando atividades de queimadas), a queima de combustíveis fósseis, as atividades de agricultura, os processos industriais e a urbanização. As categorias consideradas tendo médio impacto foram o uso de energia e o tratamento de resíduos.

O desmatamento é tido como a principal causa das mudanças climáticas. Todavia, de acordo com o Quinto Relatório de Avaliação do IPCC, a atividade com maior impacto mundial é a geração de eletricidade e energia, responsáveis por 25\% das emissões totais de CO2 em 2010 (IPCC, 2014). As causas listadas pelo IPCC se referem a níveis globais, pois no território brasileiro as atividades de maior impacto estão relacionadas à alteração do uso da terra segundo o Sistema de Estimativas e Remoções de Gases de Efeito Estufa (SEEG, 2021). As atividades ligadas a essa categoria são, principalmente, o desmatamento e queimadas. Desta maneira, pode-se dizer que a sociedade 
acadêmica tem uma noção que concorda com o IPCC sobre a principal causa das mudanças climáticas no Brasil.

Figura 2. Escala de impacto das principais causas das mudanças climáticas segundo a amostra.



Braga et al. (2011) e Antronico et al. (2020) perceberam que o desmatamento e as queimadas foram também considerados como uma das principais causas das mudanças climáticas. Entretanto, neste caso o desmatamento foi a terceira e segunda causa mais citada, respectivamente, sendo a primeira a poluição de solos e água, seguida pela emissão dos GEEs para Braga et al. (2011) e o uso excessivo de combustíveis fósseis para Antronico et al. (2020). Apesar de diferentes contextos, parece haver uma concordância de que o desmatamento está diretamente ligado às mudanças climáticas.

No que se trata da vivência prévia com eventos climáticos extremos, $89 \%$ dos interrogados já sentem ou presenciaram alguma situação climática extrema, como aumento de temperatura, redução da precipitação, aumento do número de enchentes, deslizamentos de terra, entre outros (Figura 3). Destes, os eventos mais sentidos foram o de seca, aumento da temperatura e enchentes. Assim como encontrado por Coelho et al. (2004), onde mais de $80 \%$ de sua amostra também já havia presenciado eventos similares, neste caso relacionados ao aumento de enchentes na região.

Nas categorias como deslizamentos de terra, ciclones, furacões e aumento do nível do mar, a maior parte das pessoas (>50\%) diz nunca ter experienciado nenhuma dessas situações. Entretanto, possuem conhecimento de que as mesmas são reais e acontecem, por mais que não aconteçam em um ambiente próximo.

Há uma relação direta entre a percepção de risco e vivências prévias com eventos extremos. Provou-se que aqueles que habitam em zonas de risco sentem-se mais expostos à eventos extremos e possuem, portanto, uma melhor percepção de risco (RIBEIRO et al., 2014; BURSZTYN
\& EIRÓ, 2015; DEMSKI et al., 2016; BEJA et al., 2018; RUIZ, FARIA \& NEUMANN, 2020; RUZ et al., 2020). Demski et al. (2016) inclusive percebeu que o nível de engajamento pode ser maior entre aqueles que já presenciaram eventos climáticos extremos.

Figura 3. Escala da vivência de eventos climáticos extremos da amostra.

\section{Tipo e intensidade dos eventos extremos experienciados}

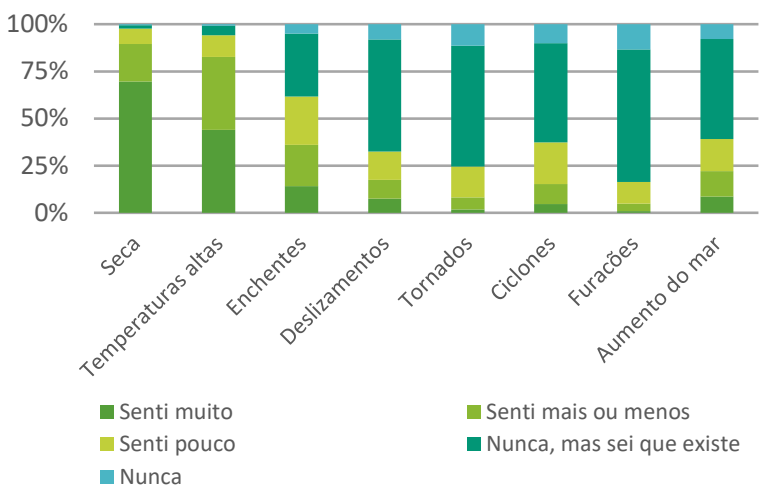

As principais alterações climáticas percebidas são na temperatura e na precipitação, como encontrado por Coelho et al. (2004), Braga et al. (2011), Fosu-Mensah et al. (2012), Roco et al. (2015) e Ernoul (2020). Os aspectos mais observados foram o aumento da temperatura, redução na precipitação e o aumento de períodos de seca.

Outra pergunta do questionário foi relacionada à noção de tempo e espaço sobre o aumento da frequência de eventos extremos (Figura 4). Estudos futuros poderão informar se há correlação entre a vivência de eventos extremos e a noção temporal e espacial do aumento deles.

Figura 4. Percepção espacial da amostra quanto ao aumento da frequência de eventos climáticos extremos em diferentes escalas espaciais.

Noção de espacialidade com relação ao aumento de eventos climáticos extremos

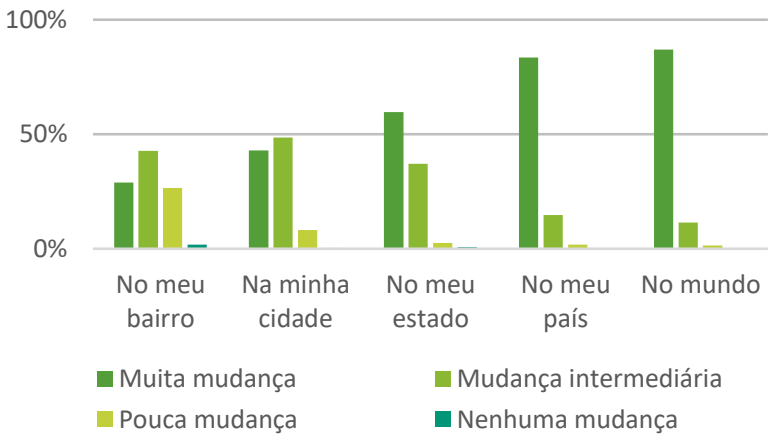


A noção temporal de $42 \%$ da amostra é de que em 5 anos a frequência de eventos extremos pode aumentar. A grande maioria (77\%) prevê que tais eventos aumentem em um horizonte de até 10 anos. Os resultados concordam com os encontrados por Bursztyn \& Eiró (2015) e Antronico et al. (2020), onde mais da metade das amostras afirmam que as consequências das mudanças climáticas são problemas atuais ou que ocorrerão em horizontes de curto prazo, enquanto outros dizem que a situação se tornará mais grave nos próximos anos, ou seja, a longo prazo.

Com relação à noção espacial dos impactos climáticos, pouco menos da metade (42\%) diz que ocorrerão mudanças intermediárias dentro de seus bairros. Já a nível de cidade, a diferença é pequena entre aqueles que acreditam que as mudanças ocorridas serão intermediárias (48\%) e grandes (42\%). De toda forma, a maior parte da amostra acredita que ocorrerão mudanças, em diferentes escalas, em ambientes próximos, como bairro e cidade.

Até então, a maioria tem uma visão de mudança intermediária em níveis mais próximos. O cenário muda quando se pergunta o tipo de impacto a nível de estado, onde mais da metade (59\%) dos respondentes disseram que haverá muita mudança nesta escala. Em níveis maiores, como nacional e mundial, esse número é muito maior, com $83 \%$ e $87 \%$, respectivamente. De maneira geral, percebe-se que os impactos serão maiores em ambientes mais longínquos e menos próximos à amostra.

Resultados similares foram encontrados por Antronico et al. (2020), onde a maioria da amostra acredita que as consequências das mudanças climáticas serão sentidas primeiro a nível mundial, e apenas em terceiro lugar pelo próprio indivíduo e seu entorno. Estes resultados são mais uma prova do conceito de otimismo espacial explorado por Pidgeon (2012) e Pinheiro et al. (2018), que consiste na tendência de um indivíduo de acreditar que menores mudanças ocorrerão em ambientes mais próximos do que a nível nacional ou mundial, havendo uma distanciação psicológica do problema. Isto impede que os indivíduos se percebam também como agentes de transformação de seu meio social. Ao perceber o problema majoritariamente em escalas maiores, ele se sente impotente diante de um problema tão complexo, facilitando assim sua inação. Há então a tendência individual de ver instituições maiores, como órgãos governamentais, como agentes com maiores escalas de ação e mais responsáveis pelas causas e soluções do problema (RUIZ et al., 2020).

A pergunta seguinte visada compreender quais os principais atores considerados responsáveis pelo combate às mudanças climáticas, levando em conta diversos níveis de atuação, partindo do próprio indivíduo e sua comunidade, passando por instituições de ensino como escolas e universidades, pelo setor corporativo, pelo terceiro setor, representado pelas Organizações NãoGovernamentais (ONGs), por instituições internacionais e, por fim, do governo (Figura 5).

Figura 5. Nível da responsabilidade de cada agente quanto à tomada de decisão e ação.

Responsabilidade quanto às mudanças climáticas

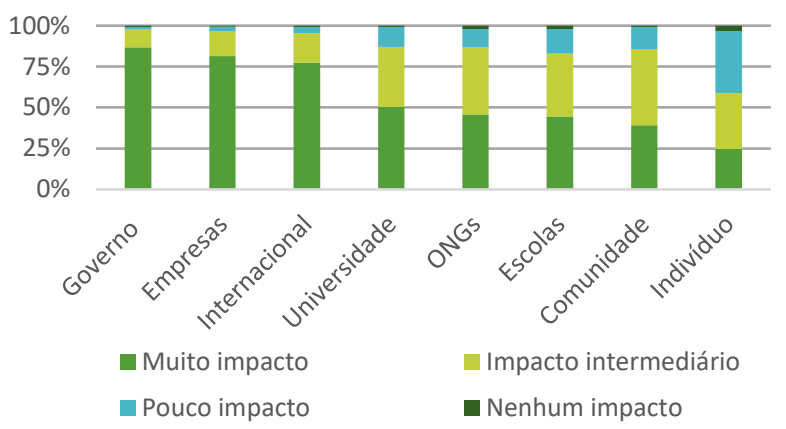

Mais da metade dos respondentes acreditam que os agentes que possuem maior impacto são o governo, as empresas e as organizações internacionais. A grande maioria dos respondentes de Mello et al. (2012) também consideram os órgãos governamentais como principais responsáveis pela redução dos riscos climáticos. Houve alteração na tendência a partir do momento em que se perguntou a respeito da responsabilidade das universidades, ONGs e escolas, onde pouco menos da metade acredita que estes agentes têm grande impacto. Com relação à comunidade, a maioria diz que as ações comunitárias causam um impacto mediano. As ações individuais foram consideradas de pequeno impacto por $38 \%$ da parcela e de médio impacto por $34 \%$, sendo o agente de menor impacto observado.

A partir dos resultados encontrados, nota-se que quanto mais pessoas envolvidas em uma mesma instituição ou organização, maior o impacto causado por ela. Além disso, há uma grande responsabilidade dada ao governo, às empresas e às organizações internacionais. Estes órgãos estão diretamente ligados à criação e implementação de políticas públicas, além de serem agentes que podem ter um grande poder influenciador. Por conta disso, as pessoas podem acreditar que tais instituições causam maior impacto por realizar ações em escalas maiores.

Tais resultados concordam com os obtidos pelo ITS-Rio, onde a maior responsabilidade foi também dada a órgãos governamentais, em seguida do setor corporativo e indústria, da população, e, por fim, das ONGs. Isto é 
explicado por Ruiz, Faria \& Neumann (2020) que dizem que os cidadãos têm uma tendência a transferir a responsabilidade para o governo e o setor corporativo.

A ordem obtida pelo ITS-Rio e pela atual pesquisa é similar, a diferença sendo que no estudo do ITS-Rio a população considera que a população em si possui mais responsabilidade que as ONGs, o que não foi percebido aqui, onde o papel da comunidade e do próprio indivíduo foram considerados menos impactantes. Nota-se então que a nível nacional as pessoas consideram a comunidade como tendo um maior impacto na redução de riscos e na tomada de ações de mitigação e adaptação, enquanto para a comunidade acadêmica as ONGs podem ter mais impacto do que ações tomadas em comunidade. A ordem de responsabilidade encontrada Barbosa et al. (2018) difere, tendo maior responsabilidade os órgãos governamentais, seguido da responsabilidade individual e do setor corporativo. Neste caso, a responsabilidade individual foi considerada maior do que a do setor corporativo, contrário do que foi encontrado pela presente pesquisa.

Apesar de haver pequena divergência nos resultados encontrados quando comparados a estudos similares, existe um consenso de que o governo é visto como o principal responsável no momento de tomada de decisão e de ação a respeito das mudanças climáticas.

Ainda assim, não se pode ignorar que a população e os indivíduos também têm papel fundamental nesse processo, podendo auxiliar na aceitação ou recusa de políticas públicas ambientais (CLAYTON et al., 2015). Esta diferença quanto aos agentes com maior e menor responsabilidade é explicada por Gifford (2011) quando diz que se torna difícil compreender o quão responsável é cada indivíduo, organização ou instituição no combate às mudanças climáticas devido a ser um problema considerado complexo e de difícil compreensão.

\section{CONCLUSÕES}

De maneira geral, a comunidade acadêmica tem um conhecimento médio sobre as mudanças climáticas, considera o assunto de grande importância e entende que é impulsionado por causas antrópicas. As principais causas consideradas são o desmatamento e o uso de combustíveis fósseis. Tais informações permitem adaptar a comunicação climática dentro da Universidade. Ao saber que grande parte compreende as principais causas das mudanças climáticas, a comunicação pode ser então direcionada a outros aspectos da situação, como ações de mitigação e adaptação.
Conhecendo as principais fontes de informação utilizadas, que são a internet, a televisão e a própria Universidade, é possível saber que tais meios devem ser explorados ao máximo para comunicar as mudanças climáticas. Mostrando que a comunicação climática é importante dentro da internet, assim como na televisão e que deve igualmente estar presente dentro da Universidade.

Segundo a amostra estudada, maiores impactos serão sentidos em até 10 anos e a níveis nacional e mundial, o que mostra que a comunidade tem uma visão pessimista, porém menos imediatista em escala temporal e uma visão otimista em escala espacial.

Percebe-se igualmente a importância de órgãos governamentais, do setor corporativo e de organizações internacionais, visto que são os agentes de ação considerados, havendo maior impacto no combate às mudanças climáticas.

Ressalta-se a importância da realização de estudos deste cunho em comunidades distintas, pois eles disponibilizam um diagnóstico do público-alvo, podendo possibilitar a criação de projetos e tomadas de ação mais efetivas.

\section{REFERÊNCIAS}

ANTRONICO, L. et al. Climate change and social perception: a case study in Southern Italy. Sustainability, v.12, n.17, p.1-24, 2020.

BARBOSA, B. et al. A importância da educação superior na percepção e compreensão de universitários do curso de educação física sobre as alterações climáticas. Revista Brasileira de Educação Ambiental, v.13, n.3, p.209-232, 2018.

BARROS, H.C.; PINHEIRO, J.Q. Mudanças climáticas globais e o cuidado ambiental na percepção de adolescentes: uma aproximação possível. Desenvolvimento e Meio Ambiente, v.40, p.189-206, 2017.

BRAGA, A.C.F.M. et al. Percepção social das mudanças climáticas na Bacia Hidrográfica do rio Gramame. $14^{\circ}$ World Water Congress, 2011.

BEJA, M. et al. Social vulnerability and risk perception a study from Madeira Island. 40 Leipzig-Evora Scientific Meeting in Psychology, p.117-127, 2019.

BURSZTYN, M.; EIRÓ, F. Mudanças climáticas e distribuição social da percepção de risco no Brasil. Sociedade e Estado, v.30, n.2, p.471-493, 2015.

COELHO, C.A. et al. A percepção social das alterações climáticas e do risco de cheia. $7^{\circ}$ Congresso da Água, p.13, 2004. 
DEMSKI, C. et al. Experience of extreme weather affects climate change mitigation and adaptation responses. Climatic Change, v.140, p.149-164, 2017.

ERNOUL, L. et al. Perception of climate change and mitigation strategies in two European Mediterranean deltas. AIMS Geosciences, v.6, n.4, p.561-576, 2020.

FEYGINA, I. et al. Localized climate reporting by TV weathercasters enhances public understanding of climate change as a local problem: Evidence from a randomized controlled experiment. Bulletin of American Meteorological Society, v.101, n.7, p.1092-1100.

FGV. Qual a faixa de renda familiar das classes? 2018. Disponível em: https://cps.fgv.br/qual-faixa-de-renda-familiar-das-classes

FOSU-MENSAH, B.Y. et al. Farmers' perception and adaptation to climate change: a case study of Sekyedumase district in Ghana. Environment, Development and Sustainability, v.14, p.495-505, 2012.

IBGE. Pesquisa Nacional por Amostra de Domicílios Contínua 2018/2019, 2019. Disponível em: https://educa.ibge.gov.br/jovens/materias-especiais/20787-usode-internet-televisao-e-celular-no-brasil.html

IPCC. Climate Change 2014: Synthesis Report. 2014. Disponível em: https://www.ipcc.ch/site/assets/uploads/2018/02/SYR_AR5 _FINAL_full.pdf

LEE, T.M. et al. Predictors of public climate change awareness and risk perception around the world. Nature Climate Change, v.5, p.1014-1020, 2015.

LENZHOLZER, S. et al. Awareness of urban climate adaptation strategies - an international overview. Urban Climate, v.34, p.119, 2020.

MELLO, A.Y.I. et al. Abordagem quantitativa em estudos sobre percepção de riscos às mudanças climáticas e ambientais: proposta no Litoral Norte de São Paulo. $6^{\circ}$ Encontro Nacional da Anppas, p.19, 2012.

PIDGEON, N. Climate change risk perception and communication: addressing a critical moment? Risk Analysis, v.32, n.6, p.951-956, 2012.

PINHEIRO, J.Q. et al. Mudanças climáticas globais: Viés de percepção, tempo e espaço. Estudos de Psicologia, v.23, n.3, p.282-292, 2018.

RIBEIRO, R.R.R. et al. Análisis de la percepción de los riesgos naturales en la Universidad de Alicante. Investigaciones Geográficas, v.61, n.61, p.147-157, 2014.

ROCO, L. et al. Farmers' perception of climate change in Mediterranean Chile. Regional Environmental Change, v.15, p.867-879, 2015.
RUIZ, I. et al. Climate change perception: Driving forces and their interactions. Environmental Science \& Policy, v.108, p.112-120, 2020.

RUZ, M.H. et al. Climate change and risk perceptions in two french coastal communities. Journal of Coastal Research, v.95, p.875879, 2020.

SEEG. Emissões Totais. 2021. Disponível em: https://plataforma.seeg.eco.br/total_emission

SHI, J. et al. Knowledge as a driver of public perceptions about climate change reassessed. Nature Climate Change, v.6, p.759762, 2016.

SHI, J. et al. Public Perception of Climate Change: The Importance of Knowledge and Cultural Worldviews. Risk Analysis, v.35, n.12, p.2183-2201, 2015.

STÜRMER, A.B. et al. Aquecimento global: percepções dos estudantes do ensino médio. Unoesc \& Ciência - ACHS, v.1, n.1, p.21-28, 2010.

XUE, S. et al. Evaluation of climate change risk perception in Baoji city based on AHP-Bayesian Network. Journal of Risk Analysis and Crisis Response, n.4, p.147-159, 2020. 